\title{
A Review of Arrests Among Psychiatric Patients
}

\author{
E. Glenn Schellenberg, ${ }^{*}$ Donald Wasylenki, ${ }^{* *}$ Christopher D. Webster, ${ }^{* * *}$ \\ and Paul Goering $* * * *$
}

Common wisdom has it that "trouble with the law" is a serious problem for psychiatric patients. This may be especially so for chronically mentally ill patients, most of whom have a diagnosis of schizophrenia. However, little is known about how often clinicians should expect to encounter this problem, or about the factors involved.

In a major review of the literature, Rabkin (1979) divided relevant studies into two groups - those published before 1965 and those published after. The earlier studies showed that arrest rates for patients were lower than rates for the general population (Ashley, 1922; Brill \& Malzberg, 1962; Cohen \& Freeman, 1945; Pollock, 1938). Studies published between 1965 and 1979 showed arrest rates of patients to be equal to, or greater than, those of the general population (Durbin, Pasewark, \& Albers, 1977; Giovanni \& Gurel, 1967; Rappeport \& Lassen, 1965, 1966; Sosowski, 1974, 1978; Steadman, Cocozza, \& Melick, 1978; Zitrin, Hardesty, \& Burdock, 1976). Rabkin (1979) attributed the increase in arrest rates to an increase in the proportion of patients with prior criminal records. It is important to note, however, that thousands of patients were "deinstitutionalized" between 1965 and 1974. The bed capacity of U.S. state hospitals diminished from 550,000 in 1961 to 110,000 by 1975 (Bassack \& Gerson, 1978), placing many more patients at risk for arrest.

Data concerning schizophrenia and risk for arrest were equivocal. Rabkin concluded that schizophrenics are no more likely to be arrested than are other diagnostic groups, with the exception of violent crime, for which schizophrenics may have higher rates of arrest. She also concluded that psychiatric patients, in general, are not predisposed to be arrested for some crimes as opposed to others, with the exception of assaultive behavior, for which they are more likely than other persons to be arrested. No conclusions could be reached concerning the effect of psychiatric hospitalization or treatment on arrest rates.

This report examines research conducted since 1980 concerned with arrest

\footnotetext{
*Graduate student, Department of Psychology, Uris Hall, Cornell University, Ithaca, NY 14853, U.S.A.

${ }^{* *}$ Head, Continuing Care Division, Clark Institute of Psychiatry, 250 College Street, Toronto, Ontario, M5T 1R8, Canada.

***Head of Psychology and Research Scientist, Clarke Institute of Psychiatry.

****Director, Health Systems Research Unit, Clarke Institute of Psychiatry.

Correspondence should be addressed to Dr. Donald Wasylenki.
} 
rates among the mentally ill. Studies that have used measures of arrestable behavior with specific reference to the legality of such acts are included.

\section{Methodological Problems}

Cohen (1980) discussed methodological flaws in literature comparing criminal activity among psychiatric patients to that in the general population. He stressed that demographic variables such as sex, age, marital status, socioeconomic status, racc, and localc must bc controlled, because all have been shown to be related to crime. Other problems arise in comparing studies. Different studies use different sample sizes, examine different populations, and employ different diagnostic categories. Small sample sizes are a problem with measures that have low baseline rates, such as arrests. Cohen suggested that "the smaller the sample size, the greater the likelihood of an inflated crime rate." The percentage of the population under study having a primary diagnosis of substance abuse should also be controlled, since substance abusers may be prone to criminal activity.

Criminal activity is usually measured by arrest rates - the number of arrests per annum per 1,000 persons. The choice of this measure seems based on the fact that these data are easy to obtain for the general public, which can then function as a comparison group. Unfortunately, arrest rates do not indicate the percentage of patients that have been arrested. Cohen (1980) cautioned that abnormally high arrest rates for patient populations may be due to a subgroup with multiple arrests. Recent studies have focused on the percentage of patients who have been arrested, an approach that is probably more useful to the clinician.

Another problem with arrest rates is that they imply guilt. Most arrests do not result in convictions. Similarly, most crimes do not result in arrest. Thus, arrest rates often underestimate the total number of arrestable incidents, and overestimate the total number of criminal convictions.

Some studies have examined psychiatric patients' contacts with the criminal justice system other than arrests. Alternative measures have included "trouble with the law," hospital admissions as a result of actions which were arrestable according to the law, "assaultive acts," and "police contact." Differences in these measures make cross-study comparisons difficult.

\section{The Research}

Studies are reviewed in chronological order, beginning with 1980.

Sosowsky (1980) investigated arrest rates of 301 psychiatric patients after hospital release as a function of prior arrest history, and in comparison with rates for the general public. Forty-one percent of patients were arrested during the follow-up period, and arrests for violent crimes represented $15.6 \%$ of all arrests. Of the $53 \%$ that had been arrested prior to hospitalization, $56 \%$ were subsequently arrested. Of those without a previous arrest, $24 \%$ were subsequently arrested. More than half the patients without previous arrests who were arrested in the follow-up period were arrested within 19 months after discharge from the hospital.

The annual arrest rate per 1,000 ex-patients was 219.3 ; this rate was five 
times the general rate in 1978 for San Mateo County, which was 38.5 per 1,000. The annual arrest rate for violent crime per 1,000 patients was 34.2 , almost 10 times the county rate of 3.5. Patients without previous arrests were subsequently arrested approximately three times as often as the general public and five times as often for violent crimes.

Goldstrom and Manderschied (1982) studied Community Support Program (CSP) patients. Their study is of particular interest because patients were involved in a long-term treatment program. Information was obtained for 1,471 of 4,287 patients. Almost all patients $(92 \%)$ had histories of psychiatric hospitalization prior to entering the CSP, with an average of 4.3 hospitalizations per patient. By collapsing data across five categories, Goldstrom and Manderschied found that only $7.3 \%$ of their sample had had any trouble with the law in the year prior to admission to the CSP.

A Canadian study of 102 chronic psychiatric patients was conducted by Finlayson, Greenland, and Dawson (1983). The sample consisted of patients who had been admitted four or more times to psychiatric facilities in the Hamilton-Wentworth region during 1977. Schizophrenia was the most common diagnosis for male patients $(27 \%)$, followed by the combined diagnoses of alcoholism and drug abuse $(22.1 \%)$. For female patients, the most common diagnoses were personality disorder (34\%) and depression (20.7\%). A primary diagnosis of substance abuse was more common among men than women.

The authors found that $69.4 \%$ of male patients and $60.4 \%$ of female patients had had "police contact" during 1977. Of the patients with police contact, male patients had an average of 4.6 contacts and female patients had an average of 4.2 contacts. The rate of police contact for the entire sample was four times the rate which would be expected for the general population.

The large sample used by Schuerman and Kobrin (1984) consisted of all patients admitted to the Los Angeles County Department of Mental Health in 1978. The authors examined arrests over a 4-year period that began before admission and extended until 1979. They examined patient arrests in relation to sex, age, and ethnicity, and in comparison to arrest rates for Los Angeles County. One out of every six patients $(16.6 \%)$ was arrested in the 4-year period from 1976-1979. One of every 14 patients (7.1\%) was arrested for at least one felony crime. The percentage of males arrested for felony crimes $(11.5 \%)$ is more than four times the percentage of females arrested for these crimes $(2.7 \%)$. Misdemeanors accounted for $75 \%$ of all arrests.

Comparing arrest rates for psychiatric patients with the adult county population, Schuerman and Kobrin (1984) found that patients had higher overall arrest rates, as well as higher rates for each crime category. Patients in the 1825 age bracket, however, had lower arrest rates than the same subgroup of the general public. The arrest rate of psychiatric patients does not decline as quickly with age as it does in the general population. Patients who were black, Hispanic, or from other minority populations (mostly Oriental), had lower overall arrest rates than their counterparts in the general public. Only the "Anglo" group had higher rates for patients. Because this group represented over half of the patient population, and because blacks, with traditionally higher arrest rates, were overrepresented in the study sample, the rates for patients in general were higher than those for the general public.

Two studies using the same data base were reported by Steadman and co- 
workers (Steadman, 1985; Steadman et al., 1984). The authors took a random sample of all male admissions to state mental hospitals in six states during 2 years, 1968 and 1978. Hospitalization in 1978 compared to 1968 was characterized by shorter stays, a drop in the mean age of patients, and an increase in the proportion of nonwhite patients.

The authors found that, in $1968,38.2 \%$ of male admissions had at least one prior arrest while, in 1978 , the proportion had risen to $55.6 \%$. Of patients admitted in $1968,5.7 \%$ had been imprisoned at some point; $8.8 \%$ of the 1978 sample had been imprisoned at some point. Of patients admitted who had at least one prior arrest, $43.2 \%$ of the 1968 group and $60.0 \%$ of the 1978 group had been arrested for a crime against a person. A greater percentage of the 1978 sample had been arrested for property crimes and for drug crimes, but the percentage of patients with prior arrests for minor crimes had fallen from 1968. The authors cautioned that the increase in arrest rates could be at least partly due to an increase in the proportions of younger patients and nonwhite patients in mental hospitals from 1968-1978 (Steadman et al., 1984).

Analyzing the data further, Steadman (1985) found that the percentage of patients with previous arrests for at least one violent crime had risen from $12 \%$ in 1968 to $20 \%$ in 1978 . Conversely, arrests for nuisance-type crimes had declined from $63 \%$ of all arrests for patients admitted in 1968 to $38 \%$ for the 1978 admissions. Steadman also found the patients admitted to the hospital with previous psychiatric hospitalizations had risen from $45 \%$ in 1968 to $54 \%$ in 1978. Patients in the 1978 sample were, therefore, characterized by higher numbers of prior mental health and criminal justice contacts, and their contacts with the law tended to be of a more serious nature.

Teplin (1987) suggested that future research into the involvement of the mentally ill in the criminal justice system investigate the effects of homelessness as an intermediary variable. Two recent studies of the homeless mentally ill begin this task. One study involved a sample taken from 8,061 people over 18 who entered 14 New York City public shelters between 1 November 1982 and 31 December 1983 (Crystal, Ladner, \& Towber, 1986). A large psychiatric subgroup was drawn from those who reported current mental health problems, current psychiatric outpatient status, or previous psychiatric inpatient status (24.9\% of the total). A diagnostic breakdown was not provided, but $34.1 \%$ of the psychiatric group reported regular past or present use of substances. Fortyfive percent of the psychiatric sample acknowledged a history of having been in jail, including $47 \%$ of those with an inpatient history and $38 \%$ of those who were currently in outpatient treatment. Having been in jail was a result of having committed a felony in the great majority of cases.

Morse and Calsyn (1986) studied a sample of 248 people receiving temporary housing in St. Louis. While only $25 \%$ had been previously hospitalized for psychiatric problems, $41.1 \%$ had received some form of psychiatric treatment, and $15.3 \%$ were in current treatment. The authors classified $19.9 \%$ as having "chronic mental health needs" and a further $35.8 \%$ as having "crisis/acute mental health needs." They found that $21.6 \%$ of the whole sample and $45.8 \%$ of the chronic group had been arrested at some point while homeless. The chronic group was significantly more likely to have been arrested than other subjects. Ten percent of the sample had been convicted and imprisoned while 
homeless. Although results from studies of the mentally ill homeless are not directly applicable to the mentally ill in general, the data support a relation between homelessness, mental illness, and involvement with the criminal justice system.

Harry and Steadman (1988) studied a random sample of patients who had their first known psychiatric contact at a Community Mental Health Centre (CMHC) in a small city in Missouri. Their sample consisted of five subgroups: (1) 98 inpatients admitted in 1975; (2) 99 outpatients admitted in 1975; (3) 102 inpatients admitted in 1983; (4) 82 outpatients admitted in 1983; and (5) 187 patients who presented at the CMHC on an emergency basis in 1983 .

For the 1975 inpatient group, $16.3 \%$ of patients were arrested within 9 years of admission, but one-quarter of the patients arrested (4.1\% of the group) were arrested in the first year after admission to the CMHC. Similarly, 5.1\% of the 1975 outpatient group were arrested over the 9 years postadmission, but $80 \%$ of these (4\% of the group) were arrested in the first year after admission. The authors concluded that patients are at high risk for arrest during their first year in the community following their first psychiatric contact, a finding congruent with Sosowsky's (1980) results.

The study did not find a significant difference in arrest rates for the 2 years studied (1975 and 1983), contrary to expectations. Their finding is not consistent with the criminalization hypothesis that suggests that tighter involuntary commitment laws have increased mentally ill patients' risk for arrest (Teplin, 1984). The only factors significant in contributing to arrest were a diagnosis of antisocial personality disorder, the number of prior arrests, and younger age. These factors accounted for only $5 \%$ of the variance.

Comparisons were made between annual arrest rates for the general population and rates for psychiatric patients during their first postadmission year. Rates for psychiatric inpatients and outpatients admitted in 1975 (41 and 40.4 per 1,000 , respectively) were lower than the rate for the statewide general population in 1975 (54 per 1,000). Inpatients admitted in 1983 had an arrest rate of 78.4 per 1,000 , which is 1.74 times greater than the rate of 45 per 1,000 for the general population for the same year. Outpatients admitted in 1983 were arrested less often during their first postadmission year $(36.6$ per 1,000$)$ than the general public. The arrest rate for emergency patients admitted in 1983 was 53.5 per 1,000 , which is 1.19 times greater than the rate for the general public. Some arrest rate data have been revised since publication, and the revisions are reported here (B. Harry, personal communication, August 2, 1989). Charges for violent crimes, including homicide, assault, child battering, rape, sodomy, and sexual abuse, represented a small proportion of the charges laid against the five psychiatric groups. For the two 1975 subgroups, of 52 arrest charges laid against 21 patients within 9 years of admission, only seven charges $(13.5 \%)$ were for violent crimes. For the three 1983 subgroups, of 34 charges laid against 21 patients during the first postadmission year, $6(17.6 \%)$ were violent.

A population of young adults with major psychiatric disorders was studied by Holcomb and Ahr (1988). The statewide random sample was composed of 611 patients who were treated as inpatients $(51 \%)$, outpatients $(47 \%)$, or in community residential care $(1.7 \%)$ at the time of their last mental health con- 
tact in Missouri in 1982. All state-operated institutions and CMHCs were sampled. Major psychiatric disorders were defined as: (1) alcohol or drug abuse $(42 \%)$; (2) schizophrenia or other psychosis $(32 \%)$; (3) major affective disorder (12\%); (4) personality disorder $(10 \%)$; and (5) organic brain syndrome (4\%). The mean number of previous psychiatric inpatient admissions was 3.27.

The authors found that $38 \%$ of their sample had been arrested at least once in their adult lifetimes. The percentage of alcohol and drug abusers who had been arrested was significantly higher than the percentage for all other diagnostic groups combined ( $47 \%$ versus $32 \%$, respectively). The percentage of the schizophrenia or other psychosis subgroup with arrest records was lower than the percentage for the sample. Thirty-eight percent of the sample had been arrested for felonies and $19 \%$ for violent crime during their adult aftercare. Patients who suffered from chronic conditions with early onset were, on the whole, found to be less likely to be arrested than other patients. The authors also examined arrest rates since admission in 1982, and they found that $8.5 \%$ of patients had been arrested within a year after treatment.

Arrests were divided into 13 categories and analyzed with respect to diagnoses. Patients with schizophrenia or other psychosis were less likely than all other diagnostic groups combined to have been arrested for the following crime categories: (1) burglary, fraud, or theft; (2) offenses against the public order; (3) drug- and alcohol-related offenses; and (4) probation and parole violations.

Holcomb and Ahr (1988) found that six variables were significant in identifying patients who had been arrested during their adult lifetimes from those who had not. Patients with arrest records were more likely to be older when their psychiatric problems began, to have a primary diagnosis of alcohol or drug abuse, to have had a longer history of public mental health care, to have been committed involuntarily on their last admission, to be from an urban county, and to be less likely to have a diagnosis of schizophrenia or other psychosis. This multiple regression analysis accounted for only $7 \%$ of the variance observed.

Patients who were arrested within 1 year after treatment were, in comparison with patients who were not arrested, more often of nonwhite race, younger, and more likely to have a higher number of lifetime felony arrests and a longer history of public mental health care. These four variables accounted for $25 \%$ of the variance.

Klassen and O'Connor $(1988,1988 \mathrm{a}, 1988 \mathrm{~b})$ published three reports which identified predictors of violence in a mentally ill population. Their sample was composed of 304 men predisposed to violent behavior. The sample was drawn from a population of inpatients admitted to an urban CMHC in Missouri who had undergone short-term treatment. The authors (Klassen \& O'Connor, 1988a) classified 239 patients as being "at risk," defined as being in the community for at least 4 of the 6 months after release. Forty-six patients (19\%) were classified as violent, defined as having been arrested for a violent crime, or readmitted for violence during follow-up. More patients were classified as violent because of a violent readmission (12.6\%), as opposed to a violent arrest $(8 \%)$, highlighting the fact that arrestable behavior often results in consequences other than arrests. 
The authors (Klassen \& O'Connor, 1988b) then studied 252 patients from the sample who were in the community for at least 3 months during the year after admission. Many more of the patients who were readmitted during this time were arrested than the patients who were not readmitted (53\% vs. $3.3 \%)$. Higher numbers of prior arrests, numbers of prior admissions, and numbers of arrests for violent crime were found for patients age 25-34, black patients, and patients who were first admitted as psychiatric inpatients before the age of 18. The best predictor of arrests during the follow-up period was the number of prior arrests. A diagnosis of substance abuse and number of prior admissions were also predictive of subsequent arrest. Arrests for violence were predicted by a diagnosis of substance abuse, prior arrests for violence, and age. Admissions for violence were predicted by the number of prior admissions and age at first admission. Violent arrestable behavior was predicted by the number of prior arrests, age, and the number of prior admissions.

Schizophrenics were found to have two admissions for violence for each arrest for violence, highlighting the methodological problem of using arrest rates as the sole measure of arrestable behavior with this subgroup. Schizophrenics had the following mean numbers of arrests and readmissions during the study time frame of 1 year: inpatient readmissions, 1.14; arrests, 1.08; arrest for violent crime, 0.16 ; readmissions for violence, 0.31 ; and total of arrests and readmissions for violence, 0.47 .

Klassen and O'Connor (1988) used the same sample to study predictors of violence in 236 schizophrenic and nonschizophrenic patients. The study period was 1 year after release from the CMHC. Schizophrenics were analyzed separately from nonschizophrenics because they were shown to be different along several demographic variables. Of the $29.7 \%$ of patients classified as violent, a higher percentage of schizophrenics were classified as such $(32 \%)$, than nonschizophrenics $(28 \%)$.

McFarland, Faulkner, Bloom, Hallanx, and Bray (1989) collected data from relatives of psychiatric patients in Oregon. The authors found that $52 \%$ of their sample were reported by family members to have been arrested at some point. Schizophrenics were found to have been arrested at the same rate as other patients. Patients with arrests had an average of 3.3 arrests. Only $19 \%$ of the sample had ever been convicted, and only 4\% had ever been imprisoned. Forty-five percent had been jailed an average of 2.6 times. Of the patients who were jailed, schizophrenics were jailed significantly less than patients with other diagnoses. While comparisons with national figures are not entirely appropriate, the authors noted that the chronic mentally ill seemed to be more likely to be jailed, and less likely to be convicted or imprisoned, than the average.

McFarland et al. (1989) used the Sourcebook of Criminal Justice Statistics, 1986 to compare the percentage of their sample that had been arrested with the population of the western states. Taking demographic variables into account, they arrived at a standardized rate of $28 \%$ of psychiatric patients with arrest histories. This rate is higher than the self-reported rate of $17 \%$ of the total population of the western states who have been arrested. The authors noted that demographic variables alone do not account for the increased proportion of the mentally ill who have been arrested. 
The authors acknowledged that their sample does not represent the general population of the mentally ill in Oregon. Surveys were sent to advocates for the mentally ill, and the sample was limited to those that chose to respond $(54 \%)$. They noted, however, that even if the response rate had been $80 \%$, and all of the additional responses had been for patients who had never been arrested, $30 \%$ of the enlarged sample would still have been reported to have been arrested. The authors conclude that being arrested is a significant problem for the chronically mentally ill.

\section{Discussion}

The percentage of patients with previous arrests varies from a low of $8 \%$ to a high of $76 \%$. Harry and Steadman (1988) report percentages that vary from 8-26\% over five study groups. These results are lower than all other comparable results reviewed. The samples studied by Harry and Steadman were composed of patients who were undergoing their first psychiatric admission, suggesting that a sizeable proportion of contact occurs after first admission. In addition, these authors studied Community Mental Health Centre rather than State hospital patients. Thus, it would be expected that subjects in their sample would be more like the general population.

Holcomb and Ahr (1988) found that $31 \%$ and $38 \%$ of their sample had been arrested at some point. These were young psychiatric patients with major mental disorders and a high proportion of substance abuse. Twenty-eight percent of the schizophrenic subgroup had been arrested.

Steadman et al. (1984) and Sosowsky (1980) reported much higher percentages of psychiatric patients with arrest records. Although the percentage of the 1968 sample in the Steadman et al. study who had been arrested $(38.2 \%)$ is similar to the findings above, $55.6 \%$ of the sample admitted in 1978 had arrest records. Similarly, Sosowsky (1980) reported that $53 \%$ of his sample had arrest records. The high percentage found by Steadman et al. can be partially attributed to the fact that only male patients were included. Sosowsky's sample, however, was only $67 \%$ male, a proportion similar to other studies with lower percentages of patients arrested. Sosowsky's results remain something of an anomaly, especially considering the fact that his sample consisted of patients admitted to and released from the hospital between 1972 and 1975. The criminalization hypothesis (Teplin, 1983, 1984) suggests that deinstitutionalization has led to a higher proportion of psychiatric patients with arrest records. According to this hypothesis, samples of patients formed early in the history of deinstitutionalization should have relatively low proportions of patients with prior arrests.

McFarland et al. (1989) reported a similar high percentage (52\%) of patients with arrest records. Sampling bias may account for part of this high rate, in that family members of patients who had been arrested may have been more likely to respond to the survey. When the authors accounted for demographic variables, the standardized rate was $28 \%$. Other researchers did not derive a standardized percentage of patients arrested, so comparisons with the McFarland et al. result are impossible.

Klassen and O'Connor $(1988,1988 \mathrm{a}, 1988 \mathrm{~b})$ used a sample composed of men 
who were predisposed to violence, which explains why $74 \%$ of their sample had been arrested. The percentage of schizophrenics in the sample with arrest records $(\mathbf{7 6 \%})$ was similar. This result is in contrast with Holcomb and Ahr's (1988) study in which schizophrenics were found to be less likely to have been arrested than the sample as a whole. Schizophrenics were not, however, found to be significantly different from the other diagnostic groups in their frequency of arrests for violent crime. These results suggest that schizophrenia as a diagnosis is not a crucial factor in the relation between mental illness and arrests for violence. A diagnosis of schizophrenia may, however, mean that a patient is less likely to have been arrested for nonviolent crimes.

The studies reviewed suggest that 4-9\% of psychiatric patients are arrested during the first year after admission. This rate was shown to decrease as the time since admission increased (Harry \& Steadman, 1988; Sosowsky, 1980). Harry and Steadman found that $3.7-7.8 \%$ of patients were arrested during the year after admission to the CMHC. Samples with a higher incidence of substance abuse had higher percentages of arrested patients. Samples of patients admitted as outpatients had lower incidences (these samples also had more females than males), suggesting a possible relation between severity of mental disorder and arrests. Holcomb and Ahr (1988) found that 8.5\% of their sample were arrested in the first postadmission year. The higher rate is attributable to the fact that they studied a younger population with major psychiatric disorders.

Sosowsky (1980) found that $41 \%$ of his sample was arrested over a maximum 6.5-year follow-up. Sosowsky also found that almost $13 \%$ of patients he studied who did not have prior arrests were arrested within 19 months after discharge, again within the 4-9\% per annum range. Likewise, Goldstrom and Manderschied (1982), whose sample was in treatment at the time of the study, found that $7.3 \%$ of patients had had "trouble with the law" during the year prior to data collection.

Schuerman and Kobrin (1984) reported similar results: $16.6 \%$ of patients were arrested in a 4-year period that included the 2 years prior to admission in addition to the 2 years after admission. Klassen and O'Connor's (1988b) results are considerably higher $(33 \%$ and $53 \%$ of patients arrested in the first postadmission year), but their sample was selected such that the baseline of arrests and arrestable behavior was higher than average.

The most common measure of violence in relation to arrests and psychiatric patients is the percentage of the total of all arrests which were arrests for violent crimes. The variance among the results reported is partially due to differences in criteria used in defining crime as violent. In most of the studies reviewed, arrests for violence represented 10-20\% percent of all arrests. Harry and Steadman (1988) reported results that were both lower and higher than the 10-20\% range, possibly due to increased error as a result of smaller sample sizes and low baseline rates of arrests. Collapsing the data across the five groups and the two follow-up periods, of the 86 total charges laid, $13(14.0 \%)$ were for violent crimes, a result within the postulated range. Schuerman and Kobrin (1984) reported that only $7.3 \%$ of all arrests were for violent crimes. Their low finding may be due to their relatively restricted criteria for violent crime, or to the nature of arrests in large urban centers. 
Two studies reviewed included the percentage of patients arrested for violent crime. Holcomb and Ahr (1988) found that 19 percent of their sample of young adults with major psychiatric diagnoses had been arrested for a violent crime during their adult lifetimes. The corresponding result for the schizophrenics in the sample was somewhat lower (15.6\%). Klassen and O'Connor (1988) reported that $39 \%$ of their violently predisposed schizophrenics and $41 \%$ of the entire sample had been arrested previously for a violent crime. Presumably, the percentages of schizophrenics and psychiatric patients in general with prior arrests for violent crime would be lower for other populations than those reported for these two "skewed" samples.

Four studies investigated arrest rates of the mentally ill as compared to those of the general public. Sosowsky (1980) found an annual arrest rate of 219.3 per 1,000 patients, compared to the rate of 38.5 per 1,000 for the San Mateo County population. Although Sosowsky found that the mentally ill are arrested at a rate five times that of the general public, others have questioned the relevance of his comparison (Monahan \& Steadman, 1983).

Schuerman and Kobrin (1984) found a rate of 459 arrests per 1,000 patients over the 4-year study period, which can be converted to an annual rate of 114.8 per 1,000. The 4-year rate for Los Angeles County was 347 arrests per 1,000 , which is equivalent to an annual rate of 86.8 per 1,000 . In this study, psychiatric patients were arrested at a rate 1.32 times that for the general public.

Harry and Steadman (1988) found similar results for two of their five samples. Inpatients and emergency patients admitted in 1983 had annual arrests rates of 78.4 and 53.5 per 1,000 , respectively. These rates were 1.74 and 1.19 times greater, respectively, than the rate for the state population, which was 45 per 1,000 (revised data from B. Harry, personal communication, August 2, 1989). Outpatients admitted in 1983, and both inpatients and outpatients admitted in 1975, had rates of arrest lower than the rates for the general public. The change in Missouri's commitment statutes in 1979 could partially explain the lower rates for patients admitted in 1975, but the 1983 outpatients' arrest rate remains unexplained. The small sample size $(N=82)$ may be a factor, as well as the apparent lack of major psychiatric diagnoses in this group.

McFarland et al. (1989) compared the percentage that had been arrested with the percentage of the population of the western states with self-reported arrest records, as found in the Sourcebook of Criminal Justice Statistics, 1986. Even after adjusting for sex and age, the standardized rate of $28 \%$ was significantly higher than the self-reported rate of $17 \%$ for the western states.

The studies reviewed here are in general agreement with the post-1965 work reviewed by Rabkin (1979). The past 25 years of research has made it safe to conclude that psychiatric patients are arrested at a rate equal to, or greater than, the rate for the general public.

The most consistent predictor of arrests in psychiatric populations is number of prior arrests (Harry \& Steadman, 1988; Holcomb \& Ahr, 1988; Klassen \& O'Connor, 1988b; Sosowsky, 1980). This fact suggests that it is not mental illness per se that leads to criminal behavior. Increased rates of arrest in psychiatric populations can often be attributed, at least in part, to an increase in the number of patients with arrest records. Other factors that are predictive for 
both the general public and psychiatric populations (i.e., age, race, and sex) also suggest that mental illness in itself does not predispose to legal deviance.

Younger patients were found in four studies to be more likely to be arrested or to exhibit arrestable behaviors (Harry \& Steadman, 1988; Holcomb \& Ahr, 1988; Klassen \& O'Connor, 1988; Steadman et al., 1984). Younger age is only a factor in increased arrest rates when arrests are considered within a specific, limited time frame. If one looks at arrests over a lifetime, the number of arrests per patient and the percentage of patients arrested can only increase with age. Schuerman and Kobrin (1984) noted that although youth was related to arrests in their sample, youth is a better predictor of arrests in the general population than it is in psychiatric populations.

Schuerman and Kobrin found that nonwhite race is predictive of arrests for the mentally ill, but race is a better predictor of increased arrests for the general public. Other studies also found a relation between nonwhite race and increased arrests (Holcomb \& Ahr, 1988; Klassen \& O'Connor, 1988).

Males were found to have more arrests or incidents of arrestable behavior in two studies (Sosowsky, 1980; Steadman et al., 1984). Sex was not predictive, however, of either a history of arrests or of postadmission arrests in the sample studied by Holcomb and Ahr (1988). McFarland et al. (1989) also found that sex was not related to a history of arrests. In the study by Finlayson et al. (1983), male and female patients had very similar levels of "police contact," but for men, "police contact" was a result of being a suspect more often than it was for women.

The significance of the relative strength of demographic variables in relation to arrests or arrestable behavior for psychiatric patients and the general public is not clear. On one hand, the same demographic variables are predictive of arrests/arrestable behavior in both populations, suggesting that mental illness per se may be unrelated to legal deviance. On the other hand, higher arrest rates for psychiatric populations and the relatively weaker strength of demographic variables as predictors for these populations, suggest that mental illness itself may be at least somewhat predictive of arrests/arrestable behavior. Although this issue remains unresolved, comparisons between the mentally ill and the general public are probably of limited importance to the practicing clinician.

No firm conclusions about the contribution of homelessness to arrests of the mentally ill can be made. However, the finding in one sample that $45 \%$ of the mentally ill homeless had been jailed, and the finding in another sample that $45.8 \%$ of the chronic mentally ill homeless had been arrested while homeless, suggest that arrest rate figures and the percentage of persons arrested would be higher than for "normal" psychiatric groups.

Previous hospitalizations may also be a factor contributing to arrests in samples of psychiatric patients. Steadman (1985) reported that patients admitted in 1978 had more previous hospitalizations and more arrests than patients admitted in 1968. Klassen and O'Connor (1988b) found prior admissions to be predictive of both arrests and violent arrestable behavior. Holcomb and Ahr (1988) found that longer histories of receiving mental health care were predictive of arrest histories and postadmission arrests. McFarland et al. (1989) found no relation between previous hospitalizations and arrest histories. 
The relation between a diagnosis of schizophrenia and arrests/arrestable behavior remains inconclusive. Klassen and O'Connor (1988) classified slightly more schizophrenics than nonschizophrenics as violent according to their criteria. Holcomb and Ahr (1988) found that schizophrenic patients were less likely than other patients to be arrested for several crime categories. Sosowsky (1980) found that the percentage of schizophrenics remained relatively constant across groups of patients with or without arrests.

A primary diagnosis of substance abuse has been found, in most studies, to increase the likelihood of arrests and arrestable behavior. Substance abuse predicted arrests and arrests for violence in Klassen and O'Connor's (1988b) study. Holcomb and Ahr (1988) found that substance abusers had the greatest overall frequency of arrests. McFarland et al. (1989) found substance abuse to be a significant predictor of an arrest history. Harry and Steadman (1988) found that a diagnosis of substance abuse was not significantly related to arrests within the year after admission, but the sample sizes for their study groups were relatively small.

\section{Conclusion}

The research to date shows that between one-third and one-half of psychiatric patients have been arrested at some point. Findings of widespread criminal justice system contact in psychiatric populations are important because these contacts may have profound effects on the mentally ill. Further research is needed to identify these effects and to examine the extent to which they affect psychiatric patients. Findings of high percentages of patients with prior arrests do not tell us about the nature of the arrests. It is possible that arrests are used by authorities to place psychiatric patients in treatment. If this is the case, then patients may be arrested for crimes that are often overlooked when committed by the general public, and the percentage of patients that have been arrested may be somewhat inflated. Even more likely is the probability that mental illness often prevents arrests, such that the percentage of patients arrested underestimates, to a greater extent than with the public at large, the percentage of persons that actually could have been arrested.

The postadmission arrest findings indicate that clinicians should expect about 1 out of every 13 patients per year to experience an arrest after admission to psychiatric treatment. Patients who are arrested may require more of a clinician's time than other patients as reports to the court may be necessary as well as legal testimony. The clinician should also expect that less than one-fifth of all arrests will be for violent crimes. Comparisons of arrest rates between psychiatric patients and the general public are not as clinically useful as other findings. Clinicians can expect the mentally ill to be arrested more often than the general public, but a higher arrest rate among patients may be due to a subgroup with multiple arrests per year. Clinicians themselves are probably unaware of, and uninterested in, arrest rates for the general public.

Certain factors that predict arrests in the general population are also predictive of arrests for psychiatric patients. Patients with prior arrests, younger patients, male patients, and nonwhite patients are more likely to be arrested than other patients. Research on the homeless mentally ill suggests that this 
subgroup is particularly prone to being arrested. Findings comparing arrests of schizophrenics with arrests of other psychiatric patients remain equivocal. Substance abusers, however, are more likely to be arrested than other patients. These factors may support the "criminalization hypothesis" to some extent, insofar as younger patients are now less likely to be admitted to hospitals for extended periods and homelessness and substance abuse are related to lack of appropriate shelter.

With regard to future trends, psychiatry has moved progressively toward the case management care model for the chronically ill, in which patients reside outside of hospital but retain close contact with a case manager. The nature of this contact differs from the usual parole/probation supervision. Case management is clinical in its orientation (Kanter, 1989). This means that the goal is to reduce symptomatology and to improve social functioning. The relationship itself is seen as a powerful therapeutic tool (Harris \& Bergman, 1987). It is possible, however, that the case management approach will result in more criminal justice system contact for the mentally ill, because patients are "on the streets" more and are therefore more "at risk." It is also possible that the case management approach has resulted in a higher functioning mentally ill population, with fewer deviant behaviors and fewer legal contacts. Bond et al. (1988) conducted a study which found no difference in number of legal system contacts between experimental groups of patients that were assertively case managed and control groups. The sample sizes were small, and more research is needed before conclusions on the effectiveness of continuing treatment and case management can be made.

\section{References}

Ashley, M. (1922). Outcome of 1000 cases paroled from the Middletown State Hospital. State Hospital Quarterly, 8, 64-70.

Bassak, E., \& Gerson, S. (1978). Deinstitutionalization and mental health services. Scientific American, 238, 46-53.

Bond, G. R., Miller, L. D., Krumweid, R. D., \& Ward, R. S. (1988). Assertive case management in three CMHCs: A controlled study. Hospital and Community Psychiatry, 39, 411-418.

Brill, H., \& Malzberg, B. (1962). Statistical report on the arrest record of male ex-mental patients released from New York State mental hospitals during the period 1946-8. In Criminal acts of ex-mental hospital patients (supplement 153). Washington, DC: American Psychiatric Association Mental Hospital Service.

Cohen, C. I. (1980). Crime among mental patients - a critical analysis. Psychiatric Quarterly, 52, 100-107.

Cohen, L., \& Freeman, H. (1945). How dangerous to the community are state hospital patients? Connecticut State Medical Journal, 9, 697-700.

Crystal, S., Ladner, S., \& Towber, R. (1986). Multiple impairment patterns in the mentally ill homeless. International Journal of Mental Health, 14, 61-73.

Durbin, J., Pasewark, R., \& Albers, D. (1977). Criminality and mental illness: A study of arrest rates in a rural state. American Journal Psychiatry, 134, 80-83.

Finlayson, R., Greenland, C., Dawson, D., Blam, H., \& Pittman, G. (1983). Chronic psychiatric patients in the community. Canadian Journal of Psychiatry, 28, 635-639.

Giovannoni, J. M., \& Gurel, L. (1967). Socially disruptive behaviour of ex-mental patients. Archives of General Psychiatry, 17, 146-153.

Goldstrom, I. D., \& Manderschied, R. W. (1982). The chronically mentally ill: A descriptive analysis from the uniform client data instrument. Community Support Service Journal, 2(3), 4-9.

Harry, B., \& Steadman, H. J. (1988). Arrest rates of patients treated at a community mental health centre. Hospital and Community Psychiatry, 39, 862-866. 
Harris, M., \& Bergman, H. C. (1987). Case management with the chronically mentally ill: A clinical perspective. American Journal of Othopsychiatry, 57, 296-302.

Holcomb, W. R., \& Ahr, P. R. (1988). Arrest rates among young adult psychiatric patients treated in inpatient and outpatient settings. Hospital and Community Psychiatry, 39, 52-57.

Kanter, J. (1989). Clinical case management: Definition, principles, components. Hospital and Community Psychiatry, 40, 361-368.

Klassen, D., \& O'Connor, W. A. (1988). Predicting violence in schizophrenic and non-schizophrenic patients: A prospective study. Journal of Community Psychology, 16, 217-227.

Klassen, D., \& O'Connor, W. A. (1988a). A prospective study of predictors of violence in adult male mental health admissions. Law and Human Behaviour, 12, 143-158.

Klassen, D., \& O'Connor, W. A. (1988b). Crime inpatient admission and violence among male mental patients. International Journal of Law and Psychiatry, 11, 305-312.

McFarland, B. H., Faulkner, L. R., Bloom, J. D., Hallaux, R., \& Bray, J. D. (1989). Chronic mental illness and the criminal justice system. Hospital and Community Psychiatry, 40, 718-723.

Monahan, J., \& Steadman, J. H. (1983). Crime and mental disorder: An epidemiological approach. In M. Tonry \& M. Morris (Eds.), Crime and justice: An annual review of research (Vol. 4). Chicago: University of Chicago Press.

Morse, G., \& Calsyn, R. J. (1986). Mentally disturbed homeless people in St. Louis: Needy, willing, but underserved. International Journal of Mental Health, 14, 74-94.

Pollock, H. H. (1938). Is the paroled patient a threat to the community? Psychiatric Quarterly, 12, 236244.

Rabkin, J. G. (1979). Criminal behavior of discharged mental patients: A critical appraisal of the research. Psychological Bulletin, 86, 1-27.

Rappeport, J. R., \& Lassen, G. (1965). Dangerousness - Arrest rate comparison of discharged patients and the general population. American Journal of Psychiatry, 121, 776-783.

Rappeport, J. R., \& Lassen, G. (1966). The dangerousness of female patients: A comparison of the arrest rate of discharged psychiatric patients and the general population. American Journal of Psychiatry, 123, 413-419.

Schuerman, L. A., \& Kobrin, J. S. (1984). Explosion of community mental health clients to the criminal justice system. In L. A. Teplin (Ed.), Mental health and criminal justice. Beverly Hills, CA: Sage.

Sosowsky, L. (1974). Violence and the mentally ill. In $`$ Putting state mental hospitals out of businessthe community approach to treating mental illness in San Mateo County. Berkeley, CA: University of California.

Sosowsky, L. (1978). Crime and violence among mental patients reconsidered in the view of the new legal relationship between the state and the mentally ill. American Journal of Psychiatry, 135, 33-42.

Sosowsky, L. (1980). Explaining the increased arrest rate among mental patients: A cautionary note. American Journal of Psychiatry, 137, 1602-1605.

Steadman, H. J. (1985). Prediction at the system level: Measuring the presumed changes in the clientele of the criminal justice and mental health system. In C. D. Webster, M. H. Ben-Aron, \& S. J. Hucker (Eds.), Dangerousness: Probability and prediction, psychiatry and public pollcy. Cambridge, UK: Cambridge University Press.

Steadman, H. J., Cocozza, J. J., \& Melick, M. E. (1978). Exploring the increased arrest rate among mental patients: The changing clientele of state hospitals. American Journal of Psychiatry, 135, 816-820.

Steadman, J. H., Monahan, J., Duffee, B., Hartstone, E., \& Robbins, P. C. (1984). The impact of state mental hospital deinstitutionalization on United States prison populations, 1986-1978. Journal of Criminal Law and Criminology, 75, 474-490.

Teplin, L. A. (1983). The criminalization of the mentally ill: Speculation in search of data. Psychological Bulletin, 94, 54-67.

Teplin, L. A. (1984). Criminalizing mental disorder: The comparative arrest rate of the mentally ill. American Psychologist, 39, 794-803.

Teplin, L. A. (1987, October). The criminalization hypothesis: Myth, misnomer or management strategy. Paper presented at NIMH-sponsored workshop.

Zitrin, A., Hardesty, A. S., Burdock, E., \& Drossman, A. K. (1976). Crime and violence among mental patients. American Journal of Psychiatry, 133, 142-149. 